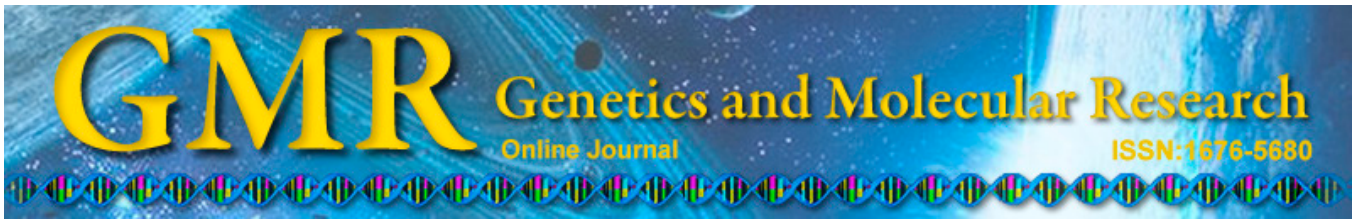

\title{
Fourier transform infrared photoacoustic spectroscopy as a potential tool in assessing the role of diet in cuticular chemical composition of Ectatomma brunneum
}

\author{
R.C. Bernardi ${ }^{1}$, E.L.B. Firmino ${ }^{1}$, M.C. Pereira ${ }^{2}$, L.H.C. Andrade ${ }^{1}$, \\ C.A.L. Cardoso ${ }^{1}$, Y.R. Súarez ${ }^{1}$, W.F. Antonialli-Junior ${ }^{1}$ and S.M. Lima ${ }^{1}$ \\ ${ }^{1}$ Programa de Pós-Graduação em Recursos Naturais, \\ Universidade Estadual de Mato Grosso do Sul, Dourados, MS, Brasil \\ ${ }^{2}$ Programa de Pós-Graduação em Entomologia e Conservação da Biodiversidade, \\ Universidade Federal da Grande Dourados, Dourados, MS, Brasil \\ Corresponding author: S.M. Lima \\ E-mail:smlima@uems.br
}

Genet. Mol. Res. 13 (4): 10035-10048 (2014)

Received May 16, 2014

Accepted August 31, 2014

Published November 28, 2014

DOI http://dx.doi.org/10.4238/2014.November.28.8

\begin{abstract}
The cuticular chemical composition plays a significant role in the recognition of nest mates in social insects, thus functioning as a chemical signature of the colony. The structure of cuticular chemicals is subject to interference from genetic and exogenous factors, including diet. In this study, various colonies of the Ectatomma brunneum ant were removed from their natural environment and housed in a laboratory to monitor the response of the cuticular chemical composition to dietary changes. Analyses were performed using gas chromatography and Fourier transform infrared photoacoustic spectroscopy, which has not been previously used for this type of analysis. The results indicate that this method is useful for analyzing biological and natural systems. We observed changes in the chemical signature with food traces in the first 30 days under feed control. Therefore, genetic information may not be
\end{abstract}


the only criterion that can be used to describe the chemical signature of a species; environmental variations also influence recognition signals. Furthermore, these results reinforce the reliability of the Fourier transform infrared photoacoustic spectroscopy method.

Key words: Chemical signals; Colony odor, Ectatomminae; Hymenoptera; Fourier transform infrared photoacoustic spectroscopy

\section{INTRODUCTION}

Social insects, particularly ants, have developed efficient system of chemical signals throughout evolution, which are the basis of the insects' social structure and allow for recognition and communication among the individuals in the colony. The ability to discriminate among nest mates has become a selective force in the evolution of insect societies (Lenoir et al., 1999). The genetic structure for the production of these chemical signals was present in early generations of ants and was retained in subsequent generations (Liénard et al., 2008). Ants function similarly to a chemical factory, producing chemicals that spread throughout their bodies in a system of more than 50 different exocrine glands (Billen, 2004); most are connected to the production of chemicals that act function in intraspecies communication, known as pheromones (Billen and Morgan, 1998). Because of their abundance, the ease of maintaining colonies in the laboratory, and the variety of behaviors displayed, ants are widely used in chemical recognition studies among social insects (Martin and Drijfhout, 2009).

Twelve functional categories of communication have been identified in social insects, which are primarily chemical in nature (Hölldobler and Wilson, 1990). The main substances responsible for coding the chemical signals of recognition in social insects are, particularly in ants, cuticular hydrocarbons (HCs), also known as superficial pheromones (Lenoir et al., 1999). In addition to their primary function in the protection against microorganisms, toxins, and desiccation (Lenoir et al., 2001), these compounds play determining roles in inter- and intraspecies recognition among nest mates and in the differentiation of castes (Lenoir et al., 1999; Antonialli Jr. et al., 2007, 2008).

Within a single species of social insects, the qualitative profile of HCs in the cuticular chemical is relatively uniform, varying only in its relative proportion according to the origin of its colony (Bonavita-Cougourdan et al., 1987). These compounds work as a common chemical signature, referred to as a "colony odor" or a "gestalt odor" (Crozier and Dix, 1979). This signature is used among nest mates to compare the chemical profile of an individual for recognition. Some of the $\mathrm{HC}$ chemicals present in the cuticule are stored in the post-pharyngeal gland and transferred among members of the colony by trophallaxis, allogrooming, and physical contact (Lenoir et al., 2001).

Signals used in intracolonial recognition are under the controls of genetic and exogenous factors derived from the nest material, seasonality and diet (Liang and Silverman 2000; Silverman and Liang 2001; Sorvari et al., 2008; Zweden et al., 2009). Therefore, variation in the chemical profile of the cuticule is a complex system of chemical communication among these insects.

The effect of exogenous factors on the composition of cuticular chemical was discussed by Gamboa et al. (1986), who examined different colonies of the Polistes fuscatus wasp species under homogeneous laboratory conditions. They observed that after controlling external factors, including diet, wasps were unable to distinguish among individuals of dif- 
ferent colonies, indicating that the cuticular profiles had become homogeneous. Other studies revealed that diet modifies the chemical recognition of ants and that the amount as well as the quality of the food can cause changes (Liang and Silverman 2000; Silverman and Liang 2001; Sorvari et al., 2008). Thus, the diet appears to significantly affect the construction of the colony's chemical signature, interfering with behavior.

The most frequently used method to evaluate cuticular chemical composition in insects is gas chromatography (GC). However, Fourier transform infrared photoacoustic spectroscopy (FTIR-PAS) was introduced to analyze compounds such as hydrocarbons and proteins in ants and wasps (Antonialli Jr. et al., 2007, 2008; Neves et al., 2012, 2013). The effectiveness of this technique has been demonstrated in several studies involving other sample types (Lima et al., 2008; Andrade et al., 2008; Almeida et al., 2012). The versatility of the photoacoustic detection method allows for the optical analyses of opaque materials in the mid-infrared region, and the FTIR-PAS can be applied in a variety of systems. Mid-infrared absorption is sensitive to vibrations in molecular chemical groups; thus, functional groups and the types of chemical bonds involved in the sample can be identified and distinguished (Smith, 1999). The low-intensity radiation regime, under which this technique operates, ensures efficiency when reading fragile materials such as biological compounds, indicating the nondestructive character of the technique (Greene et al., 1992). There have been few studies examining the biological characteristics of Ectatomma brunneum ant species Smith 1858, despite its widespread occurrence. This species has a vast distribution in Latin America, and is present mainly from Panama to Argentina (Brown, 1958), including Brazil, and is generally located in open areas, such as forest edges or glades, crops, pastures, and secondary forests (Kempf, 1972). The nest architecture of this species includes underground tunnels and chambers and is not complex (Lapola et al., 2003). Similar to other predatory ants, the diet of E. brunneum is based mainly on proteins and carbohydrates (Evans and Pierce, 1995); the protein is generally derived from terrestrial arthropods (Marques et al., 1995). In ants, sugar is used as a primary energy source for adult workers, while protein is mainly used for egg development and larvae growth (Brian, 1983).

However, the effects of environmental factors on the composition of cuticular chemicals, particularly in ants remain unclear. In this study, the effect of diet on the cuticular chemical composition in the E. brunneum ant species was evaluated using GC and FTIR-PAS. This is the first study to use FTIR-PAS for this type of analysis; we compared the results to those of GC.

\section{MATERIAL AND METHODS}

\section{Material analysis}

Four colonies of E. brunneum were collected, 3 of which were nested near the campus of the Universidade Estadual do Mato Grosso do Sul (22 ${ }^{\circ} 11^{\prime} 53.32^{\prime \prime} \mathrm{S}$ and $\left.54^{\circ} 55^{\prime} 50.90^{\prime \prime} \mathrm{W}\right)$ in an area with a predominance of grasses and shrubs. The fourth colony was located a few meters from a semideciduous area $\left(22^{\circ} 12^{\prime} 45.78^{\prime \prime} \mathrm{S}\right.$ and $\left.54^{\circ} 54^{\prime} 43.15^{\prime \prime} \mathrm{W}\right)$, according to the classification system of the Instituto Brasileiro de Geografia e Estatística, IBGE (Veloso et al., 1991). Both locations were on the edges of rural areas. Sampling was performed in December 2012 and February, March, and April 2013.

Immediately after collection, approximately 15 workers were separated, anesthetized, and sacrificed by freezing to serve as a control sample that had only eaten a natural diet. The 
remaining individuals from the colony were transferred to the laboratory and placed into artificial nests for control physical and feeding conditions. The nests were attached to an area of individual foraging for each colony, in which there was water and honey available daily and, on alternate days, larvae in the last stage of Tenebrio molitor. The number of larvae provided was related to the number of individuals in the colony.

Due to the absence in the literature of a specific period needed to establish any effect over the cuticular chemical composition, colonies were kept under controlled conditions for 30 days until the first analysis. The number of individuals used in each analysis ranged from 9 to 15 according to the size of the population to avoid compromising colony maintenance until the end of the experiment. Sampling was also performed and analyzed at 60 days. All individuals were processed similarly to the control specimens; as soon as samples were collected, they were anesthetized, sacrificed, and frozen.

Analyses were performed on the gaster, which was extracted using microsurgical tweezers and scissors. This region was chosen because it has the greatest concentration of $\mathrm{CHs}$ in the insects (Cuvillier-Hot et al., 2001).

To evaluate whether dietary compounds were present in the cuticle consuming a controlled diet, both honey and the T. molitor larvae were evaluated. Thirty final-stage larvae of T. molitor, after anesthetization and sacrifice at low temperature, were separated in the same proportion and analyzed by FTIR-PAS and GC. Six samples of the same honey used in the experiment were separated for analysis.

\section{FTIR-PAS}

For FTIR-PAS, the gaster and the $T$. molitor larvae were dried in a vacuum desiccator for $48 \mathrm{~h}$ to reduce the water content, which can interfere with infrared analyses. There was no preparation for the honey reading.

FTIR-PAS was performed using a Nicolet Nexus 670 spectrophotometer (Thermo Scientific, Waltham, MA, USA) in the spectral region of 4000-400/cm, which covers the fingerprint region $(1500-400 / \mathrm{cm})$. The spectrometer was purged with dry compressed air to remove any water vapor and $\mathrm{CO}_{2}$. The photoacoustic cell was purged with helium gas before each reading. Carbon black was used as a reference to collect the spectrum of the infrared source. New reference spectra were acquired every $100 \mathrm{~min}$. Sample spectra were obtained with an average of 128 sample scans and a resolution of $16 / \mathrm{cm}$.

\section{GC with flaming ionization detection (GC-FID)}

The CHs were extracted from the gaster with $5 \mathrm{ml}$ of hexane (HPLC-VETEC) in an ultrasonic bath for $3 \mathrm{~min}$. After filtration, the solvent was eliminated in an exhaust chamber, and the dry extract was dissolved in $100 \mu \mathrm{L}$ of hexane for GC-FID analyses.

The GC-FID (Focus, GC, Thermo Scientific-San Jose, CA, USA) was equipped with a capillary column OV-5 from the maker Ohio (Ohio, USA), that was composed by $5 \%$ phenyl dimethylpolysiloxane, with the dimensions of $30 \mathrm{~m}$ long $\mathrm{x} 0.25 \mathrm{~mm}$ diameter $\mathrm{x} 0.25 \mu \mathrm{m}$ thickness of film. Nitrogen was used as loader gas at a constant pressure of 0.8 Bar. Analyses were performed in splitless mode with injection of $1 \mu \mathrm{L}$. The injector and detector temperature was adjusted at $300^{\circ} \mathrm{C}$. The oven temperature was as follows: heat was increased from 50 to $85^{\circ} \mathrm{C}$ 
at a rate of $5^{\circ} \mathrm{C} / \mathrm{min}$; the temperature was then increased at a rate of $8^{\circ} \mathrm{C} / \mathrm{min}$ to $280^{\circ} \mathrm{C}$; finally, temperature was increased at a rate of $10^{\circ} \mathrm{C} / \mathrm{min}$ until $300^{\circ} \mathrm{C}$, which was held for $35 \mathrm{~min}$. Chromatograms were recorded using the GC solution software (Shimadzu, Kyoto, Japan). Chemicals were identified based on the pattern of linear hydrocarbons of $\mathrm{C}_{20}-\mathrm{C}_{31}(10 \mu \mathrm{g} / \mathrm{mL}$ in hexane) by comparing retention times.

\section{GC-mass spectrometry (MS)}

To evaluate the relationship between food types, the chemical compounds of honey and T. molitor were extracted in $5 \mathrm{~mL}$ hexane (HPLC-VETEC) in an ultrasonic bath for 60 min. After filtration, the supernatants were removed in an exhaust chamber and the dry extracts were dissolved in $100 \mu \mathrm{L}$ hexane for GC-MS analysis.

GC-MS analyses were performed in a gas chromatograph (GC-17, Shimadzu) equipped with a MS detector (QP 5050). The device used a capillary column of fused silica DB-5 (J\&W, $5 \%$ phenyl dimethyl polysiloxane; Agilent Technologies, Santa Clara, CA, USA), with $30 \mathrm{~m}$ long $\times 0.25 \mathrm{~mm}$ diameter $\times 0.25 \mu \mathrm{m}$ thick film under the following conditions: helium bearer gas $(99.999 \%$, flow speed of $1.0 \mathrm{~mL} / \mathrm{min}) ; 1 \mu \mathrm{L}$ injection volume; split ratio of $(1: 20)$, with an initial oven temperature of $50^{\circ} \mathrm{C}$, maintained for $30 \mathrm{~min}$; the temperature was then increased to $85^{\circ}$ at $5^{\circ} \mathrm{C} / \mathrm{min}$, and then increased to $280^{\circ}$ at $3^{\circ} \mathrm{C} / \mathrm{min}$, maintained for $30 \mathrm{~min}$; the injector temperature was $250^{\circ} \mathrm{C}$ and the temperatures of the quadrupole detector and transfer line were $280^{\circ} \mathrm{C}$. The MS scan parameters included electron impact ionization voltage at $70 \mathrm{eV}$, mass range from 45 to $600 \mathrm{~m} / \mathrm{z}$, and scan time interval of $0.5 \mathrm{~s}$. Identifications were performed by comparing the mass spectra obtained in the QP5050 Libraries (NIST 2.0) and literature data (Adams, 2001). Linear alkanes were confirmed using a standard mixture of $\mathrm{C}_{8}$ and $\mathrm{C}_{31}(10 \mu \mathrm{g} /$ $\mathrm{mL}$ in hexane) by comparing retention times.

\section{Statistical analysis}

Possible variations among the control and diet-controlled groups were examined using discriminant function analysis, separating the variables for infrared absorption intensities and corresponding wavenumbers of the photoacoustic spectrum, as well as the relative area of the selected alkanes in the GC-FID. This statistical method identifies a linear combination of the variables to better explain differences among the groups analyzed. The distance squared of Mahalanobis was used to perceive changes between the control and the 2 different periods when maintaining a controlled diet.

\section{RESULTS}

The infrared absorption spectra obtained by FTIR-PAS for the control samples and the controlled-diet of 30- and 60-day groups are shown in Figure 1 for colony \#1. Fifteen functional groups of the greatest relevance in the range $3625-500 / \mathrm{cm}$ were separated and identified; they were mainly found to be related to the HCs and the protein. These peaks are listed in Table 1 with their corresponding wavenumbers and respective vibrational modes, identified from the data reported in the literature (Lin-Vien et al., 1991; Smith, 1999). Visual identification of distinctions among the spectra was not always possible; therefore, absorption intensi- 
ties were used to construct a matrix to determine whether a statistically significant difference existed.

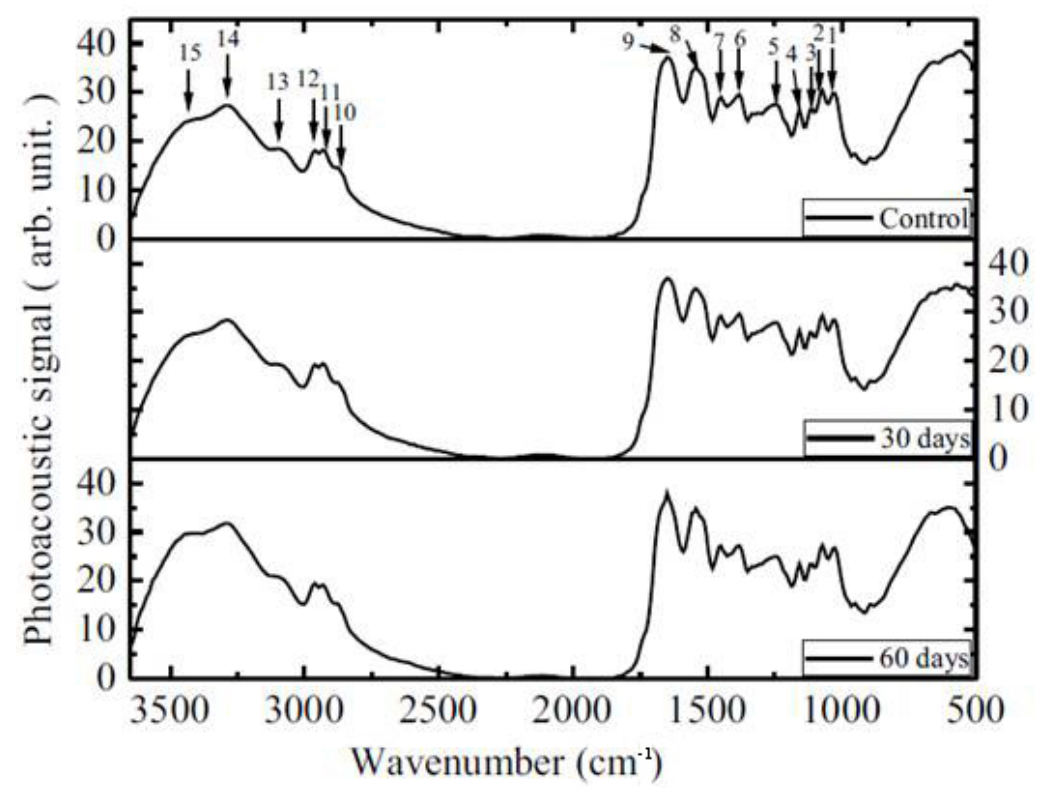

Figure 1. Average infrared absorption spectra of gasters from ants of colony \#1 generated by FTIR-PAS. The upper panel shows the control samples, the middle represents the samples after 30 days in the laboratory, and the lower panel shows samples after 60 days under a controlled diet. The arrows indicate the 15 peaks of greatest relevancy that were statistically analyzed.

Table 1. Relationship between the 15 main functional groups and their respective vibrational modes selected for the statistical analysis.

\begin{tabular}{|c|c|c|c|}
\hline Peak & Wave No. $\left(\mathrm{cm}^{-1}\right)$ & Functional group & Vibration mode \\
\hline 1 & 1041 & $\mathrm{C}-\mathrm{H}$ & Bending in the plane \\
\hline 2 & 1079 & $\mathrm{C}-\mathrm{H}$ & Bending in the plane \\
\hline 3 & 1110 & $\mathrm{C}-\mathrm{H}$ & Bending in the plane \\
\hline 4 & 1157 & $\mathrm{C}-\mathrm{H}$ & Bending in the plane \\
\hline 5 & 1241 & $\mathrm{CH}_{3}-\mathrm{CO}$ & Symmetric stretching \\
\hline 6 & 1396 & $\mathrm{CH}_{3}^{3}$ & Symmetric deformation \\
\hline 7 & 1457 & $\begin{array}{l}\mathrm{CH}_{3}^{3} \\
\mathrm{CH}_{2}\end{array}$ & Asymmetric stretching deformation \\
\hline 8 & 1542 & $\mathrm{NH}_{2}$ and/or $\mathrm{CN}$ (Amida II) & Twist in the plane and/or Asymmetric stretching \\
\hline 9 & 1650 & $\mathrm{C}=\mathrm{C}$ cis alkenes and/or $\mathrm{C}=\mathrm{N}$ (Amida $\mathrm{I})$ & Stretching \\
\hline 10 & 2877 & $\mathrm{CH}_{3}$ & Symmetric stretching \\
\hline 11 & 2931 & $\mathrm{CH}_{2}^{3}$ & Asymmetric stretching \\
\hline 12 & 2962 & $\mathrm{CH}_{3}^{2}$ & Asymmetric stretching \\
\hline 13 & 3093 & $-\mathrm{N}-\mathrm{H}$ & Overtone bending \\
\hline 14 & 3293 & $-\mathrm{N}-\mathrm{H}$ & Stretching \\
\hline 15 & 3425 & $-\mathrm{N}-\mathrm{H}$ & Stretching \\
\hline
\end{tabular}

The results obtained by statistical analysis revealed a clear distinction between the control group and the controlled-diet groups (Wilk's lambda $=0.006, \mathrm{~F}=22.135$ and $\mathrm{P}<$ 0.001); this is shown in the scatterplot in Figure 2. The first canonical root explained $88 \%$ of this distinction, and the peak that most contributed to this observation was located at $3425 / \mathrm{cm}$. 


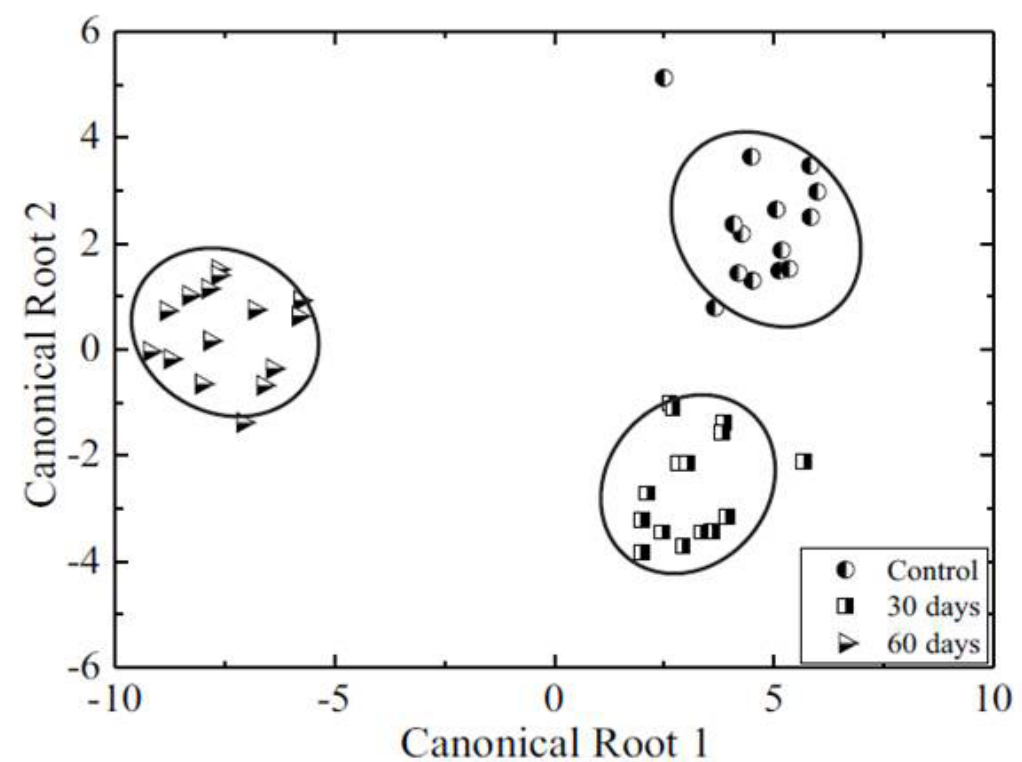

Figure 2. Scatterplot of the control, 30- and 60-days controlled diet groups, for colony \#1, from analysis of the 15 selected peaks in the infrared spectra.

Chromatography analyses were performed in the same samples from colony \#1 as described above; the linear HCs of alkanes from $\mathrm{C}_{20}$ to $\mathrm{C}_{31}$ were observed as listed in Table 2 with the corresponding retention time used for the analysis. Values of the relative areas of the HCs were used as variables for discriminant function analysis. The results generated by GCFID enforce those found by FTIR-PAS (Wilk's lambda $<0.001, \mathrm{~F}=513.460$ and $\mathrm{P}<0.001$ ), as observed in the clear separation between the scatterplot shown in Figure 3, with the first canonical root explaining $89 \%$ of the difference. Based on this analysis, the most important alkanes for the separation of groups were $\mathrm{C}_{20}, \mathrm{C}_{23}, \mathrm{C}_{25}$, and $\mathrm{C}_{27}$. The presence of the same alkanes was also observed in the chromatography analysis of diet, which is among the alkanes with a higher relative percentage (Table 3 ). In addition to the alkanes, other volatile compounds, such as phytol, which is specifically associated with honey and aldehydes related to aroma, were also found in the reading of dietary items.

Table 2. Retention time by GC-FID of hydrocarbons analyzed in colony \#1.

\begin{tabular}{llc}
\hline Alkane & Nomenclature & Retention time (min) \\
\hline $\mathrm{C}_{20}$ & $n$-eicosane & 27.87 \\
$\mathrm{C}_{21}$ & n-heneicosane & 29.32 \\
$\mathrm{C}_{22}$ & $n$-docosane & 30.47 \\
$\mathrm{C}_{23}$ & $n$-tricosane & 31.73 \\
$\mathrm{C}_{24}$ & $n$-tetracosane & 32.79 \\
$\mathrm{C}_{25}$ & $n$-pentacosane & 33.93 \\
$\mathrm{C}_{26}$ & $n$-hexacosane & 34.96 \\
$\mathrm{C}_{27}$ & n-heptacosane & 36.18 \\
$\mathrm{C}_{28}$ & n-octacosane & 37.52 \\
$\mathrm{C}_{29}$ & n-nonacosane & 39.08 \\
$\mathrm{C}_{30}$ & $n$-triacontane & 40.87 \\
$\mathrm{C}_{31}$ & $n$-hentriacontane & 43.01 \\
\hline
\end{tabular}




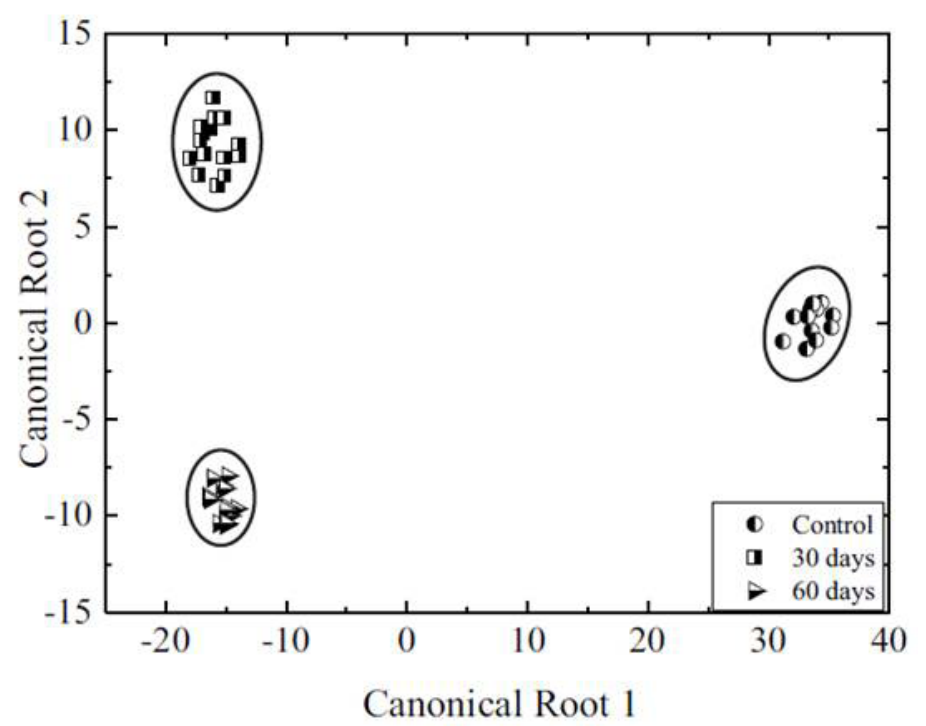

Figure 3. Scatterplot of the control, 30- and 60-days controlled diet groups, for colony \#1, from analysis of the main HCs peaks identified by GC-FID.

Table 3. Compounds present in the diets of Tenebrio molitor and honey and their relative proportions.

\begin{tabular}{llcc}
\hline & Compounds & \multicolumn{2}{c}{ Concentration (\%) } \\
\cline { 3 - 4 } & & Tenebrio molitor & Honey \\
\hline $\mathrm{C}_{18}$ & $n$-octadecane & 1.4 & - \\
$\mathrm{C}_{19}$ & Pentadecanal & - & 0.4 \\
& $n$-nonadecane & 1.7 & 1.7 \\
$\mathrm{C}_{20}$ & Octadecanal & 3.2 & - \\
$\mathrm{C}_{21}$ & $n$-eicosane & 0.7 & 0.12 \\
$\mathrm{C}_{22}$ & $n$-heneicosane & - & 1.6 \\
& $n$-docosane & 73.6 & 2.1 \\
$\mathrm{C}_{23}$ & Phytol & - & 1.3 \\
$\mathrm{C}_{24}$ & Nonadecanal & - & 4.5 \\
$\mathrm{C}_{25}$ & n-tricosane & - & 5.7 \\
$\mathrm{C}_{26}$ & $n$-tetracosane & 2.9 & 0.2 \\
$\mathrm{C}_{27}$ & $n$-pentacosane & 2.9 & 9.1 \\
$\mathrm{C}_{29}$ & $n$-hexacosane & 0.1 & 0.11 \\
$\mathrm{C}_{30}$ & $n$-heptacosane & 0.11 & 47.8 \\
$\mathrm{C}_{31}$ & $n$-nonacosane & 0.1 & 21.4 \\
\hline
\end{tabular}

The results obtained using both techniques for colony \#1 revealed that the chemical profile changed over time through the 60 days of the controlled diet. Additionally, statistical analysis indicated very good agreement for the first canonical roots for both techniques. Therefore, to analyze the experimental data for the 4 colonies, as well the T. molitor and honey diets, only the FTIR-PAS technique was used.

For subsequent samples, the same 15 peaks described above were subjected to statistical analysis (Table 1). The infrared absorption spectra generated for each group, the control group, and the 30- and 60-day controlled-diet groups for colonies \#2, \#3, and \#4 showed no clear difference between peak intensities. However, statistical analysis was performed to 
identify differences between control and controlled diet samples. For this analysis, all control samples from colonies $\# 1, \# 2, \# 3$, and $\# 4$ were considered to be a unique control group; this was also used for the 30- and 60-day controlled diet samples. We considered all samples together to avoid any possible genetic and environmental contributions to the results. The results of statistical analysis are shown in Figure 4, demonstrating significant differences among groups (Wilk's lambda $=0.337, \mathrm{~F}=6.972$ and $\mathrm{P}<0.001$ ). The first canonical root explained $86 \%$ of the difference. This analysis indicated that 8 vibrational modes were responsible for the separation of the control, 30-day, and 60-day groups (Table 4). The results confirmed that in the first 30 days under a controlled diet, changes in the cuticle chemical profile occurred; this difference compared to the control was increased after 60 days (Figure 4). Table 5 shows that the squared Mahalanobis distance increased between the control and the time under controlled feeding, a pattern that also occurred with the F values shown in Table 6.

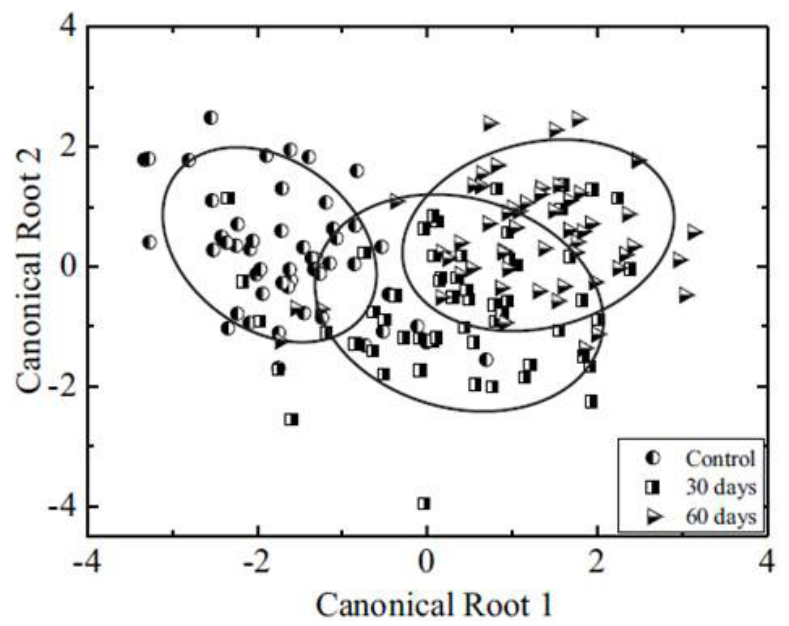

Figure 4. Scatterplot of the control, 30- and 60-days controlled diet groups, generated from the combination of data for the 4 colonies of Ectatomma brunneum, from analysis of the 15 selected peaks in the infrared spectra.

Table 4. Results of the discriminant function analysis from the variables and the more significant peaks (featured) of the cuticular chemical composition profile obtained for the FTIR-PAS of the 4 colonies, including the control and controlled-diet groups (30 and 60 days).

\begin{tabular}{|c|c|c|c|c|c|c|}
\hline Peak & Wavenumber $\left(\mathrm{cm}^{-1}\right)$ & Wilk's Lambda & $\mathrm{F}$ & $P$ & Root 1 & Root 2 \\
\hline 1 & 1041 & 0.34 & 0.43 & 0.649 & 0.55 & -0.04 \\
\hline 2 & 1079 & 0.36 & 4.30 & 0.015 & -2.10 & 0.45 \\
\hline 3 & 1110 & 0.34 & 1.43 & 0.242 & 0.49 & -1.18 \\
\hline 4 & 1157 & 0.34 & 1.54 & 0.217 & -0.23 & -1.37 \\
\hline 5 & 1241 & 0.36 & 4.18 & 0.017 & 0.88 & 0.22 \\
\hline 6 & 1369 & 0.33 & 0.21 & 0.804 & -0.04 & 0.29 \\
\hline 7 & 1457 & 0.35 & 1.88 & 0.156 & -0.41 & -0.86 \\
\hline 8 & 1542 & 0.35 & 3.68 & 0.028 & -1.44 & -0.34 \\
\hline 9 & 1650 & 0.36 & 5.67 & 0.004 & 1.57 & 0.56 \\
\hline 10 & 2877 & 0.36 & 4.93 & 0.008 & 1.86 & -0.27 \\
\hline 11 & 2931 & 0.34 & 0.89 & 0.410 & -0.09 & 1.51 \\
\hline 12 & 2962 & 0.34 & 1.03 & 0.359 & -0.67 & -1.02 \\
\hline 13 & 3093 & 0.35 & 4.64 & 0.011 & -0.31 & -1.88 \\
\hline 14 & 3293 & 0.41 & 15.71 & $<0.001$ & -2.67 & 0.49 \\
\hline 15 & 3425 & 0.44 & 21.40 & $<0.001$ & 2.55 & -0.09 \\
\hline
\end{tabular}


Table 5. Squared Mahalanobis distances between the control and controlled-diet group (30 and 60 days) for the 4 colonies.

\begin{tabular}{lccc}
\hline Groups & Control & 30 days & 60 days \\
\hline Control & 0.00 & 4.75 & 8.09 \\
30 days & 4.75 & 0.00 & 1.88 \\
60 days & 8.09 & 1.88 & 0.00 \\
\hline
\end{tabular}

Table 6. F value for the control and controlled-diet groups (30 and 60 days) for the 4 colonies.

\begin{tabular}{lrcr}
\hline Groups & Control & 30 days & 60 days \\
\hline Control & & 7.79 & 13.03 \\
30 days & 7.79 & 3.14 & 3.14 \\
60 days & 13.03 & 3.14 & \\
\hline
\end{tabular}

The average infrared absorption spectra of the controlled diet and control groups are presented in Figure 5. The gaster spectra for the ants under a controlled diet (for 30 and 60 days) were not shown because they were similar to the results for the control group. Some of the functional groups, for which there exhibited higher or lower absorptions for foods, stood out as the more significant groups for the separation among the groups, which confirms the interference of diet in the variation observed.

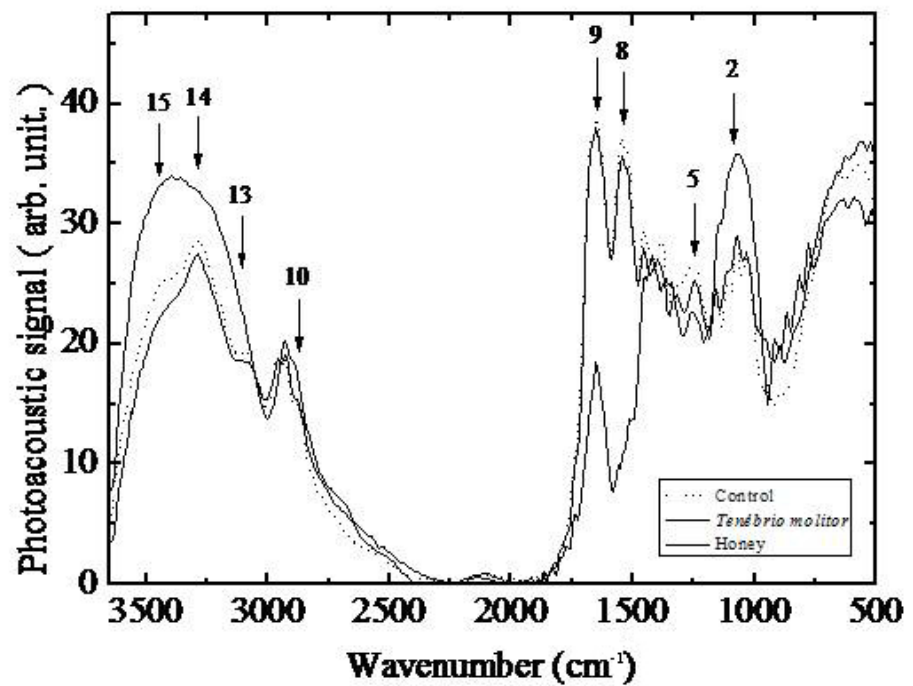

Figure 5. Average infrared absorption spectra from the union of the 4 colonies of Ectatomma brunneum for the control, 30- and 60-days controlled diet groups, as well as for the food used in the laboratory for the ants: honey and Tenebrio molitor.

\section{DISCUSSION}

The results for both GC-FID and FTIR-PAS in the study of the chemical composition of the gaster from colony \#1 revealed that external factors significantly influence chemical signature changes of individuals under feeding control compared to those exposed to a natural diet. 
Similarly to the results for colony \#1 by chromatography, Zweden et al. (2009) reported changes in the alkanes $\mathrm{C}_{25}$ and $\mathrm{C}_{27}$ in studies with the species Camponotus aethiops fed the same diet of larva of T. molitor and honey. In their study, the HCs of T. molitor were characterized mainly by 3 linear alkanes, $\mathrm{C}_{25}, \mathrm{C}_{27}$, and $\mathrm{C}_{29}$, but Bursell and Clements (1967) described the importance of an additional alkane, $\mathrm{C}_{31}$. These results deviate from the results in our study of the larvae of $T$. molitor, which showed the highest relative percentage of alkanes $\mathrm{C}_{22}, \mathrm{C}_{24}, \mathrm{C}_{25}$, and $\mathrm{C}_{26}$. This variation may be due to the analyses of the internal and external compounds of the sample, which differed from the results reported by Zweden et al. (2009) and Bursell and Clements (1967), who analyzed only larvae cuticles. These results help to explain some of the differences observed regarding the greater influence of alkanes, particularly the HCs of T. molitor.

Graddon et al. (1979) analyzed honey by using chromatography and detected nearly 160 volatile compounds present in this food, including $\mathrm{C}_{23}-\mathrm{C}_{31}$, which the authors predicted to be derived from wax. Thus, we observed these compounds likely because they were in the diet of the colonies under controlled feeding.

The chromatography results showed high alkane content $\left(\mathrm{C}_{20}, \mathrm{C}_{23}, \mathrm{C}_{25}\right.$, and $\left.\mathrm{C}_{27}\right)$, and only $\mathrm{C}_{20}$ was not present at a higher concentration in honey compared to previously values reported $\left(\mathrm{C}_{23}, \mathrm{C}_{25}, \mathrm{C}_{27}\right.$, and $\left.\mathrm{C}_{29}\right)$, whereas in the larvae, only the alkane $\mathrm{C}_{25}$ was among the prominent alkenes (Table 3). Compared to T. molitor, the honey showed higher interference in these variations.

Chemical composition analysis for the 4 colonies of ants combined and for the control group under a controlled diet revealed clear interference of external factors with this pheromone, beginning immediately after the first 30 days. The same pattern, with rapid initial alteration of the chemical profile, was also observed in another study examining the chemical signature in social insect species exposed to an altered environment, particularly diet alteration (Lenoir et al., 1999; Liang and Silverman, 2000; Sorvari et al., 2008; Zweden et al., 2009). This result can be explained in part by the processes of trophallaxis and allogrooming. This behavior should accelerate the rapid distribution of new substances among members of the colony, activating part of the recognition system (Crozier and Dix, 1979; Lenoir et al., 1999; Soroker et al., 2003).

As shown in Figure 4, dispersion among the ellipsis of the 3 evaluated groups was lower compared to the scatterplot generated by statistical analysis with only colony \#1 (Figure 2). This characteristic was likely observed because of genetic variations and environmental differences present among the 4 colonies. This shows that even with a genetic influence, the groups were identified according to their exogenous influences, which are a natural diet or 30- or 60-day controlled diet.

Various studies have reported that the cuticular chemical profiles change over time based on the season, material variation for nest construction, and, particularly, diet alterations (Lahav et al., 2001). Our results are from colonies kept under similar and constant physical conditions. Therefore, it is likely that the variations observed are consequences of diet alteration.

The results of Lenoir et al. (2001) support the hypothesized importance of exogenous factors in the odor profile of the colony. The author reports that newly emerged workers have a cuticular profile that differs from the rest of the colony, but these differences are diluted over time as social interactions occur. Thus, external factors aggregate to the genetic factors in the construction of the colonial chemical signature, as observed in this study.

In Figure 5, the most relevant peaks obtained from statistical analysis for differentiating between the control group and controlled groups are indicated. The T. molitor and the 
honey spectra were not similar, but the T. molitor spectrum was similar to the control group spectrum. Among the most relevant peaks in Figure 5, as indicated by statistical analysis, peaks $2,8,9,14$, and 15 were the most different from the control spectrum. Of these, peak 15 was the most important for the first canonical root, indicating that honey most significantly contributes to the chemical changes in the gasters of E. brunneum.

The results for statistical analysis of FTIR-PAS were very similar to those obtained by chromatography, from which it was observed that the alkanes present in the carbohydrate diet had a higher influence on the most significant cuticular chemical composition for the differentiation between the groups. This characteristic supports the results of Brian (1983), who showed that sugar is the main source of energy for adult workers and that proteic items are utilized for the development of immature ants. Similar results, in which diet was shown to be a decisive factor in the construction of surface pheromone composition, were found by Liang and Silverman (2000), who kept 2 groups of colonies of the Linepithema humile ant species in a laboratory for 56 days under various proteic diets of Blattella germanica and Supella longipalpa. The results showed that dietary compounds changed the chemical signature, and the compounds present in the 2 species showed the same change in their cuticular chemical profiles. Sorvari et al. (2008) showed complementary information regarding the Formica aquilonia ant species; in addition to the composition, the amount of food also affected the chemical signature of the colonies and, consequently, intracolonial recognition ability. It should be noted that the quality, not the quantity, of the diet may have affected the variations because the colonies under artificial conditions were kept under similar conditions.

Our results confirmed those of previous studies showing that for various ant species, exogenous factors, particularly diet, are determining factors in cuticular chemical composition. Therefore, genetic factors may not be the only factors affecting the chemical signature of a species; when environmental variations become homogenized, recognition signals also become homogenized, and diet was shown to have a major role in this process. In addition, these results reinforce the reliability of FTIR-PAS as an analytical tool for biological systems because of its specificity and reproducibility.

\section{ACKNOWLEDGMENTS}

Research supported by Agência Brasileira de Inovação (FINEP), Coordenação de Aperfeiçoamento de Pessoal de Nível Superior (CAPES), and Conselho Nacional de Desenvolvimento Científico e Tecnológico (CNPq).

\section{REFERENCES}

Adams RP (2001). Identification of Essential Oil Components by Gas Chromatography/Mass Spectroscopy. Allured Publishing Corporation, Carol Stream.

Almeida FS, Lima SM, Andrade LH and Suarez YR (2012). Differentiation of neotropical fish species with statistical analysis of fourier transform infrared photoacoustic spectroscopy data. Appl. Spectrosc. 66: 782-785.

Andrade LHC, Freitas PG, Mantovani BG, Figueiredo MS, et al. (2008). Detection of soybean rust contamination in soy leaves by FTIR photoacoustic spectroscopy. Eur. Phys. J. Spec. Top. 153: 539-541.

Antonialli WF Jr. Lima SM, Andrade LH and Suarez YR (2007). Comparative study of the cuticular hydrocarbon in queens, workers and males of Ectatomma vizottoi (Hymenoptera, Formicidae) by Fourier transform-infrared photoacoustic spectroscopy. Genet. Mol. Res. 6: 492-499.

Antonialli WF Jr. Suarez YR, Izida T, Andrade LH, et al. (2008). Intra- and interspecific variation of cuticular hydrocarbon composition in two Ectatomma species (Hymenoptera: Formicidae) based on Fourier transform infrared photoacoustic 
spectroscopy. Genet. Mol. Res. 7: 559-566.

Billen J (2004). Morphology of exocrine glands in social insects with special emphasis on the contributions by Italian researchers. Ins. Soc. Life 5: 69-75.

Billen J and Morgan ED (1998). Pheromone Communication in Social Insects-sources and Secretions. In: Pheromone communication in social insects: ants, wasps, bees, and termites (Vander Meer RK, Breed MD, Espelie KE and Winston ML, eds). West-view Press, Boulder, 3-33.

Bonavita-Cougourdan A, Clement JL and Lange C (1987). Nestmate recognition: the role of cuticular hydrocarbons in the ant Camponotus vagus Scop. J. Entomol. Sci. 22: 1-10.

Brian MV (1983). Social Insects, Ecology and Behavioral Biology. Chapman and Hall, London.

Brown WR Jr (1958). Contributions toward a reclassification of the Formicidae. II Tribe Ectatomminae (Hymenoptera). Bull. Mus. Comp. Zool. 118: 173-362.

Bursell E and Clements AN (1967). The cuticular lipids of the larva of Tenebrio molitor L. (Coleoptera). J. Insect Physiol. 13: $1671-1678$

Crozier RH and Dix MW (1979). Analysis of two genetic models for the innate components of colony odor in social Hymenoptera. Behav. Ecol. Sociobiol. 4: 217-224.

Cuvillier-Hot V, V, Cobb M, Malosse C and Peeters C (2001). Sex, age and ovarian activity affect cuticular hydrocarbons in Diacamma ceylonense, a queenless ant. J. Insect Physiol. 47: 485-493.

Evans JD and Pierce NE (1995). Effects of diet quality and queen number on growth in Leptothoracine ant colonies (Hymenoptera: Formicidae). J. New York Entomol. Soc. 103: 91-99.

Gamboa GJ, Reeve HK and Pfennig DW (1986). The evolution and ontogeny of nestmate recognition in social wasps. Ann. Rev. Entomol. 31: 431-454.

Graddon AD, Morrison JD and Smith JF (1979). Volatile constituents of some unifloral Australian honeys. J. Agric. Food Chem. 27: 832-837.

Greene RV, Gordon SH, Jackson MA, Bennett GA, et al. (1992). Detection of fungal contamination in corn: potential of PAS-FTIR and DRS. J. Agric. Food Chem. 40: 1144-1149.

Hölldobler B and Wilson EO (1990). The Ants. Belknap Press, Cambridge.

Kempf WW (1972). Catálogo abreviado das formigas da região neotropical (Hymenoptera: Formicidae). Stud. Entomol. 15 (1-4): 1-344.

Lahav S, Soroker V, Vander Meer RK and Hefetz A (2001). Segregation of colony odor in the desert ant Cataglyphis niger. J. Chem. Ecol. 27: 927-943.

Lapola DM, Antonialli WF Jr and Giannotti E (2003). Arquitetura de ninhos da formiga neotropical Ectatomma brunneum F. Smith, 1858 (Formicidae, Ponerinae) em ambientes alterados. Rev. Bras. Zoociências 5: 177-188.

Lenoir A, Fresneau D, Errard C and Hefetz A (1999). Individuality and colonial identity in ants. In: Information Processing in Social Insects (Detrain C, Deneubourg JL and Pasteels J, eds.). Birkhauser-Verlag, Basel, Switzerland, 219-237.

Lenoir A, Cuisset D and Hefetz A (2001). Effects of social isolation on hydrocarbon pattern and nestmate recognition in the ant Aphaenogaster senilis (Hymenoptra, Formicidae). Insectes Soc. 48: 101-109.

Liang D and Silverman J (2000). "You are what you eat": diet modifies cuticular hydrocarbons and nestmate recognition in the Argentine ant, Linepithema humile. Naturwissenschaften 87: 412-416.

Liénard MA, Strandh M, Hedenstrom E, Johansson T, et al. (2008). Key biosynthetic gene subfamily recruited for pheromone production prior to the extensive radiation of Lepidoptera. BMC Evol. Biol. 8: 270.

Lima SM, Izida T, Figueiredo MS, Andrade LHC, et al. (2008). Analysis of biodiesel and frying vegetable oils by means of FTIR photoacoustic spectroscopy. Eur. Phys. J. Spec. Top. 153: 535-537.

Lin-Vien D, Colthup NB, Fateley WG and Grasselli JG (1991). Infrared and Raman Characteristic Frequencies of Organic Molecules. Academic Press, Waltham.

Marques OM, Viana CHP, Kamoshida M, Carvalho CAL, et al. (1995). Hábitos de nidificação e alimentares de Ectatomma quadridens (Fabricius, 1793) (Hymenoptera, Formicidae) em Cruz das Almas-Bahia. Insecta 4: 1-9.

Martin S and Drijfhout F (2009). A review of ant cuticular hydrocarbons. J. Chem. Ecol. 35: 1151-1161.

Neves EF, Andrade LH, Suarez YR, Lima SM, et al. (2012). Age-related changes in the surface pheromones of the wasp Mischocyttarus consimilis (Hymenoptera: Vespidae). Genet. Mol. Res. 11: 1891-1898.

Neves EF, Montagna TS, Andrade LHC, Súarez YR, et al. (2013). Social parasitism and dynamics of cuticular hydrocarbons in paper wasp of the Mischocyttarus. J. Kansas Entomol. Soc. 86: 69-77.

Silverman J and Liang D (2001). Colony disassociation following diet partitioning in a unicolonial ant. Naturwissenschaften 88: 73-77.

Smith BC (1999). Infrared Spectral Interpretation: A Systematic Approach. CRC Press, Boca Raton.

Soroker V, Lucas C, Simon T, Fresneau D, et al. (2003). Hydrocarbon distribution and colony odour homogenization in Pachycondyla apicalis. Insect Soc. 50: 212-217. 
Sorvari J, Theodora P, Turillazzi S, Hakkarainen H, et al. (2008). Food resources, chemical signaling, and nestmate recognition in the ant Formica aquilonia. Behav. Ecol. 19: 441-447.

Veloso HP, Rangel Filho ALR and Lima JCA (1991). Classificação da Vegetação Brasileira Adaptada a um Sistema Universal. IBGE, Departamento de Recursos Naturais e Estudos Ambientais, Rio de Janeiro, Brasil.

Zweden JSV, Dreier S and D'Ettorre P (2009). Disentangling environmental and heritable nestmate recognition cues in a carpenter ant. J. Insect Physiol. 55: 158-163. 